\title{
Shear stress stimulates phosphorylation of protein kinase A substrate proteins including endothelial nitric oxide synthase in endothelial cells
}

\author{
Yong Chool Boo, \\ ${ }^{1}$ Department of Molecular Medicine \\ Kyungpook National University School of Medicine \\ Daegu 700-422, Korea \\ ${ }^{2}$ Corresponding author: Tel, 82-53-420-4946; \\ Fax, 82-53-426-4944; E-mail, ycboo@knu.ac.kr
}

Accepted 19 January 2006

Abbreviations: BAECs, bovine aortic endothelial cells; CaM, calmodulin; CREB, CAMP responsive element binding protein; eNOS, endothelial nitric oxide synthase; L-NAME, nitro-L-arginine methyl ester; PI3K, phosphoinositide 3-kinase; PKA, protein kinase A

\begin{abstract}
Fluid shear stress plays a critical role in vascular health and disease. While protein kinase A (PKA) has been implicated in shear-stimulated signaling events in endothelial cells, it remains unclear whether and how PKA is stimulated in response to shear stress. This issue was addressed in the present study by monitoring the phosphorylation of endogenous substrates of PKA. Shear stress stimulated the phosphorylation of CAMP responsive element binding protein (CREB) in a PKA-dependent manner. Western blot analysis using the antibody reactive against the consensus motif of PKA substrates detected two proteins, P135 and P50, whose phosphorylation was increased by shear stress. The phosphorylation of P135 was blocked by a PKA inhibitor, H89, but not by a phosphoinositide 3-kinase inhibitor, wortmannin. Expression of a constitutively active PKA subunit stimulated P135 phosphorylation, supporting the potential of P135 as a PKA substrate. P135 was identified as endothelial nitric oxide synthase (eNOS) by immunoprecipitation study. PKA appeared to mediate shear stress-stimulated eNOS activation. Shear stress stimulated intracellular translocation of PKA activity from 'soluble' to 'particulate' fractions without involving cellular cAMP increase. Taken together, this study suggests that shear stress stimulates PKA-dependent pho-
\end{abstract}

sphorylation of target proteins including eNOS, probably by enhancing intracellular site-specific interactions between protein kinase and substrates.

Keywords: cyclic AMP responsive element-binding protein; endothelial cells; nitric oxide synthase type III; protein kinase $\mathrm{A}$

\section{Introduction}

Endothelial cells are constantly subjected to shear stress generated by blood flow. Shear stress regulates vascular tone and diameter, inflammatory responses, hemostasis, vessel wall remodeling and other vascular functions (Resnick et al., 2003). Laminar shear stress has been proposed to play anti-atherogenic roles by inhibiting some of the key pro-atherogenic events including apoptosis of endothelial cells and binding of monocytes to endothelium (Cunningham and Gotlieb, 2005). Various receptors present on the surface of endothelial cells and other mechanosensing machinery allow vessels to detect subtle changes in shear stress (Davies, 2002; Dusserre et al., 2004; Fleming et al., 2005). The signal is transmitted through many intracellular pathways such as mitogen-activated protein kinase cascade, via sequential phosphorylations, the activation of transcription factors and subsequent gene expression (Berk et al., 2002).

There have been indications that protein kinase A (PKA) signaling is involved in critical cellular events stimulated by shear stress. For example, PKA activity appears to be essential for shear stress-mediated chromatin remodeling which regulates gene expression in endothelial cells (Illi et al., 2003). However, it remains controversial whether and how PKA is stimulated by shear stress. Typically PKA is activated by cAMP-dependent mechanism (Brandon et al., 1997), but there are conflicting reports with regard to the effect of fluid shear stress on cellular cAMP level. Shear stress has been observed to elevate cellular cAMP level in osteoblasts (Reich et al., 1990), but not in endothelial cells (Malek et al., 1993). Nonetheless, evolving evidences have suggested that PKA can also be activated without involving cAMP increase, by phosphorylation of Thr197 in the activation loop of PKA catalytic subunit (Cheng et al., 1998), and interaction with caveolin-1 (Razani et al., 
1999), A-kinase anchoring protein 110 (Niu et al., 2001) or $I_{\kappa} B$ protein (Dulin et al., 2001).

Unlike most other protein kinases, it has been difficult to determine the status of PKA activity in response to certain stimuli in the cells. If the activity is measured with protein extracts in which cAMP is inevitably altered, it cannot represent in situ enzyme activity. Measuring cellular cAMP is not decisive either since PKA can be activated by cAMP-independent mechanisms as well. Accordingly, various efforts have been devoted to monitor PKA activity in the cells, including a fluorescent indicator protein in which two green fluorescent protein variants are joined by the kinase-inducible domain of CAMP responsive element binding protein (CREB) (Nagai et al., 2000). Phosphorylation of known endogenous substrates of PKA has also been determined for the same purpose. For example, phosphorylation of vasodilator-stimulated phosphoprotein (VASP), a substrate for CAMP and CGMP-dependent protein kinases, was shown to be stimulated in endothelial cells exposed to fluid shear stress (Wei et al., 2003).

In the present study, in an attempt to determine in situ PKA activation by shear stress in endothelial cells, I chose to monitor phosphorylation of known and unknown endogenous targets of PKA. For the detection of unknown targets, I took advantage of the specific antibody raised against the consensus sequence of PKA substrates. Results of the current study supported PKA stimulation by shear stress.

\section{Materials and Methods}

\section{Cell culture and shear stress treatments}

Bovine aorta endothelial cells (BAECs) harvested from descending thoracic aortas were maintained $\left(37^{\circ} \mathrm{C}, 5 \% \mathrm{CO}_{2}\right)$ in a growth medium [Dulbecco's modified Eagle's medium (DMEM) containing $1 \mathrm{~g} / \mathrm{l}$ glucose (Gibco) and $20 \%$ fetal bovine serum (FBS, Atlanta Biologicals) without antibiotics] (Boo et al., $2002 b)$. BAECs used in this study were between passages 5 and 10 .

A confluent monolayer of BAECs grown in 100 $\mathrm{mm}$ culture dish (Falcon) was exposed to laminar shear stress in a low serum-containing medium (phenol red-free DMEM containing $0.5 \%$ FBS and $25 \mathrm{mM}$ Hepes, $\mathrm{pH} 7.4$ ) by rotating a Teflon cone $\left(0.5^{\circ}\right.$ cone angle) as described previously (Boo et al., 2002a; b). Cells were exposed to an arterial level of shear stress $\left(15 \mathrm{dyn} / \mathrm{cm}^{2}\right)$.

\section{Expression vectors and transfection}

PKA-Cqr construct was a kind gift from Dr. G. Stanley McKnight, University of Washington. PKA-Cqr is a constitutively active mutant of mouse PKA catalytic subunit $\mathrm{C} \alpha$ which contains double mutations (His87Gln and Trp196Arg) (Orellana and McKnight, 1992). The entire coding sequence of PKA-Cqr was sub-cloned into a bi-cistronic vector, pAdTrackCMV (a kind gift from Dr. Bert Vogelstein, Johns Hopkins University) which also expresses green fluorescent protein.

BAECs were transfected with plasmid vectors by using lipofectamin (Invitrogen). Cells grown to $-90 \%$ confluency in $100 \mathrm{~mm}$ culture dishes were washed with and kept in $5 \mathrm{ml}$ of Opti-MEM (Gibco). Five $\mu \mathrm{g}$ DNA and $10 \mu \mathrm{g}$ lipofectamin were mixed with $500 \mu \mathrm{l}$ Opti-MEM and the mixture was kept at room temperature for $30 \mathrm{~min}$. Cells were treated with the mixture for $5 \mathrm{~h}$ at $37^{\circ} \mathrm{C}$. The transfected cells were incubated further for $1 \mathrm{~d}$. When BAECs were transfected with pAdTrackCMV vector, the transfected cells were conveniently monitored by fluorescence microscopy for green fluorescent protein expression, revealing typical transfection efficiency $\sim 50 \%$ (data not shown).

\section{Adenoviral infection}

BAECs were infected at $\sim 90 \%$ confluency with a recombinant adenovirus in serum-free DMEM for 1 $\mathrm{h}$ and then incubated $48 \mathrm{~h}$ in a growth medium. The recombinant adenoviral construct, Ad-Akt-Myr, was used to express a constitutively active Akt mutants generated by fusing a myristoylation signal to its amino terminus (Fujio and Walsh, 1999; Boo et al., 2002b). Recombinant adenovirus encoding $\beta$ galactosidase (Ad- $\beta$-gal) was used as a control.

\section{Preparation of cell lysates and Western blot}

Following any treatment, BAECs were washed with ice-cold PBS and lysed in $0.75 \mathrm{ml}$ of ice-cold lysis buffer A $(20 \mathrm{mM}$ Tris- $\mathrm{HCl}, \mathrm{pH} 7.6,150 \mathrm{mM} \mathrm{NaCl}$, $1 \mathrm{mM}$ EDTA, $1 \mathrm{mM}$ EGTA, $2.5 \mathrm{mM}$ sodium pyrophosphate, $1 \mathrm{mM} \beta$-glycerophosphate, $1 \mathrm{mM}$ sodium vanadate, $1 \mu \mathrm{g} / \mathrm{ml}$ leupeptin, $1 \mathrm{mM}$ PMSF, $1 \mu \mathrm{M}$ microcystin, and $1 \%$ Triton $\mathrm{X}-100)$. Cell lysates were clarified by spinning at $14,000 \mathrm{rpm}$ for $15 \mathrm{~min}$ at $4^{\circ} \mathrm{C}$. For the extraction of CREB, cells were lysed in lysis buffer $B(10 \mathrm{mM}$ Tris- $\mathrm{HCl}, \mathrm{pH} 7.6,1 \mathrm{mM}$ sodium vanadate and $1 \% \mathrm{SDS}$ ). The lysates were further homogenized by repeated aspiration through a 25-gauge needle. Protein content of each sample was measured by using a Bio-Rad DC assay.

Aliquots of cell lysates (20 $\mu \mathrm{g}$ protein each) were resolved on a $10 \%$ SDS-PAGE gel and transferred to a polyvinylidene difluoride membrane (Millipore). The membrane was incubated with a primary antibody overnight at $4^{\circ} \mathrm{C}$ and then with a secondary antibody conjugated with alkaline phosphatases ( 1 $\mathrm{h}$ at room temperature), which was detected by a chemiluminescence method, as described previously 
(Boo et al., 2002a). Blots shown are representatives of at least 3 independent studies.

\section{Immunoprecipitation}

For the immunoprecipitation studies, monoclonal endothelial nitric oxide synthase (eNOS) antibody or non-immune $\lg G$ was bound to protein $\mathrm{G}$-agarose beads by incubating for $1 \mathrm{~h}$ at $4^{\circ} \mathrm{C}$. The beads containing $1 \mu \mathrm{g}$ bound antibody were added to an aliquot of the cell lysates (200 $\mu \mathrm{g}$ protein) and incubated for $1 \mathrm{~h}$ at $4^{\circ} \mathrm{C}$. The mixture was centrifuged at 1,500 $\mathrm{rpm}$ for $30 \mathrm{sec}$ to pellet the bead from supernatant, and the beads were washed with buffer $A$ three times. The beads and the supernatant were analyzed by Western blot.

\section{Antibodies}

Phospho-PKA substrate (RRXS*/T* where $T^{*}$ and $S^{*}$ denote phosphorylated threonine and serine) rabbit polyclonal antibody was purchased from Cell Signaling Technology. The antibody detects peptides and proteins containing a phospho-Ser/Thr residue with arginine at the -3 and -2 positions. Polyclonal antibodies specific for phospho-Ser1179-eNOS and phospho-Ser635-eNOS were from Cell Signaling Technology and Upstate Biotechnology, respectively. Monoclonal antibody specific for phospho-Ser133CREB and polyclonal antibody for CREB were from Cell Signaling Technology. Monoclonal and polyclonal antibody for eNOS and monoclonal antibody for PKA-C $\alpha$ were obtained from Transduction Laboratories. Polyclonal antibody for total Akt was from Santa Cruz biotechnology.

\section{eNOS activity assay}

eNOS activity was assayed by measuring the conversion of $\mathrm{L}$-arginine to $\mathrm{L}$-citrulline. BAEC monolayers were washed with ice-cold PBS twice and then scraped into $1 \mathrm{ml}$ of ice-cold PBS. Cells were collected by centrifugation at 10,000 rpm for $2 \mathrm{~min}$. To prepare cell lysates, cells were suspended in $100 \mu$ of ice-cold lysis buffer C (50 mM Tris- $\mathrm{HCl}$ $(\mathrm{pH} 7.4), 1 \%$ NP-40, 0.1\% mercaptoethanol, 10 $\mathrm{mM} \mathrm{NaF}, 1 \mathrm{mM}$ sodium vanadate, $2 \mu \mathrm{g} / \mathrm{ml}$ aprotinin, $10 \mu \mathrm{g} / \mathrm{ml}$ soybean trypsin inhibitor, and $1 \mathrm{mM}$ PMSF). The protein extract was passed through a column of Dowex cation exchange resin pre-equilibrated with the lysis buffer, to remove endogenous L-arginine which might interfere with the assay. The flowthrough fractions (40 $\mu$ g protein) were incubated in $50 \mu \mathrm{l}$ of reaction mixture containing $1 \mathrm{mM} \mathrm{NADPH}$, $1 \mu \mathrm{M}$ FAD, $1 \mu \mathrm{M}$ FMN, $30 \mu \mathrm{M}$ BH4, $10 \mu \mathrm{M}$ Larginine- $\mathrm{HCl}(10 \mu \mathrm{mol} / \mathrm{L}),\left[{ }^{3} \mathrm{H}\right]-\mathrm{L}$-arginine $(66 \mathrm{Ci} /$ mmol, $0.2 \mathrm{mCi}), 0.6 \mathrm{mM} \mathrm{CaCl}_{2}$ and $100 \mathrm{nM}$ cal- modulin (CaM) for $40 \mathrm{~min}$ at $37^{\circ} \mathrm{C}$. $\mathrm{Ca}^{2+} / \mathrm{CaM}-$ independent enzyme activity was measured in replicate samples by omitting $\mathrm{CaCl}_{2}$ and $\mathrm{CaM}$ from the incubation. All assays were carried out in the absence or presence of eNOS inhibitor nitro-L-arginine methyl ester (L-NAME, $1 \mathrm{mM}$ ). Incubations were terminated by adding $1 \mathrm{ml}$ of ice-cold stop buffer (20 mM HEPES, 5 mM EDTA, pH 5.5). [ $\left.{ }^{3} \mathrm{H}\right]$-L-Arginine was separated from $\left[{ }^{3} \mathrm{H}\right]$-L-citrulline by passing the entire reaction mixture over a column of Dowex cation exchange resin. The effluent containing $\left.{ }^{3} \mathrm{H}\right]$-L-citrulline was collected and quantified by liquid scintillation counting.

\section{PKA activity assay}

After treatment, cells were washed twice with PBS and then scraped into $0.75 \mathrm{ml}$ of extraction buffer (20 mM K-P, pH 7.0, $400 \mathrm{mM} \mathrm{NaCl,} 2$ mM EDTA, $0.2 \mathrm{mM} 3$-isobutyl-1-methylxanthine, $50 \%$ glycerol, $1 \mathrm{mM}$ PMSF). The collected cells were homogenized with a glass homogenizer on ice for $30 \mathrm{sec}$. The cell homogenate was centrifuged at $15,000 \mathrm{rpm}$ for $15 \mathrm{~min}$ to separate supernatant and pellet. The pellet was suspended into $0.75 \mathrm{ml}$ of extraction medium by repeated pipetting. Both supernatant and pellet fractions were subjected to PKA activity assay using an assay kit from Upstate biotechnology. PKA activity to PKA substrate peptide Kemptide $(100 \mu \mathrm{M})$, was assayed in $50 \mu \mathrm{l}$ of reaction buffer $(20 \mathrm{mM}$ 4-morpholine propanesulfonic acid, $\mathrm{pH} 7.2,25 \mathrm{mM}$ $\beta$-glycerolphosphate, $5 \mathrm{mM}$ EGTA, $1 \mathrm{mM}$ sodium vanadate, $1 \mathrm{mM}$ dithiothreitol, $15 \mathrm{mM} \mathrm{MgCl} 2,100$ $\mu \mathrm{M}$ ATP, $\left[\gamma^{32}{ }^{32} \mathrm{P}\right]$ ATP $(2,000 \mathrm{cpm} / \mathrm{pmol}), 0.4 \mu \mathrm{M}$ of protein kinase $\mathrm{C}$ inhibitor peptide, $4 \mu \mathrm{M}$ CaMdependent protein kinase inhibitor R24574, $2 \mu \mathrm{M}$ CAMP) in the presence and absence of PKA inhibitor $(1.2 \mu \mathrm{M} \mathrm{PKI})$. After $15 \mathrm{~min}$ at $25^{\circ} \mathrm{C}$, aliquots of reaction mixture were blotted on the p81 paper squares. The assay squares were washed three times with $0.75 \%$ phosphoric acid, once with acetone and then dried for scintillation counting. The data were presented as PKI-inhibitable phosphorylation of Kemptide.

\section{Statistical analysis}

Statistical analysis was performed by Student's $t$-test. The $P<0.05$ based on at least 3 or more independent experiments was considered to be statistically significant.

\section{Results and Discussion}

\section{Shear stress stimulates CREB phosphorylation by a PKA-dependent mechanism}

To examine whether PKA is stimulated by shear 
A

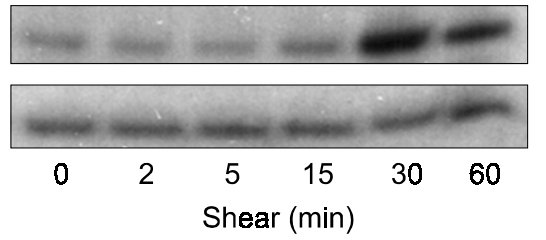

C

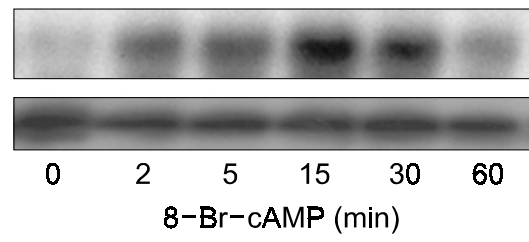

$\mathrm{pS}^{133}-\mathrm{CREB}$

CREB

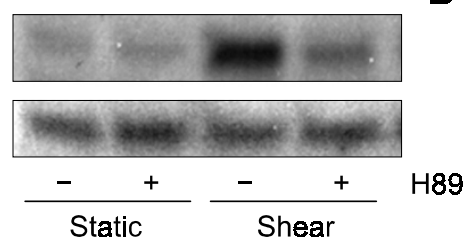

D

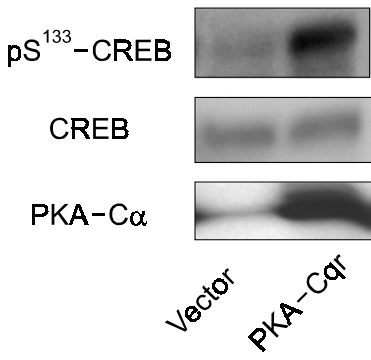

Figure 1. Shear stress stimulates CREB phosphorylation by a PKA-dependent mechanism in endothelial cells. In A, BAECs were exposed to shear stress $\left(15 \mathrm{dyn} / \mathrm{cm}^{2}\right)$ for the indicated time. In $\mathrm{B}$, cells were pretreated with vehicle (DMSO) or a PKA inhibitor $(10 \mu \mathrm{M}$ H89) for $30 \mathrm{~min}$ before exposure to shear stress for 30 $\mathrm{min}$. In the separate experiments, cells were treated with 8-Br-cAMP $(1 \mathrm{mM})$ for indicated time $(\mathrm{C})$, or transfected with an empty vector $(5 \mu \mathrm{g}$ DNA/dish) or PKA constructs expressing a constitutively active PKA catalytic subunit mutant (PKA-Cqr) (D). The cell lysates were analyzed by Western blot using antibody specific to phospho-Ser133-CREB. The membranes were re-probed with an antibody detecting total CREB to monitor equal loading of samples. PKA-Cqr was detected by PKA-C $\alpha$ antibody.

stress, I first explored the phosphorylation of CREB, one of the well known regulatory targets of PKA (Daniel et al., 1998; Park et al., 2003; Min et al., 2004). When the BAECs were exposed to shear stress, there was a significant increase in CREB phosphorylation at Ser133, maximizing at $30 \mathrm{~min}$ from the onset of shear stress (Figure 1A). Since other protein kinases including CaM kinases are also known to phosphorylate CREB (Sheng et al., 1991), additional experiments were carried out to verify the association of PKA. As shown in Figure 1B, the shear-stimulated CREB phosphorylation was abrogated when the cells were pretreated with a highly selective PKA inhibitor, H89. The identity of CREB as a regulatory target of PKA could be verified by independent experiments where PKA was stimulated by treating cells with a cell permeable cAMP analog, 8-Br-CAMP (Figure 1C), or expressing a constitutively active PKA catalytic subunit mutant, PKA-Cqr (Figure 1D). These results implicated that shear stress stimulated PKA pathway in endothelial cells.

\section{Shear stress stimulates phosphorylation of putative PKA substrates}

As an independent approach to examine in situ PKA activation in cells, the putative endogenous targets of PKA were monitored for their phosphorylation by

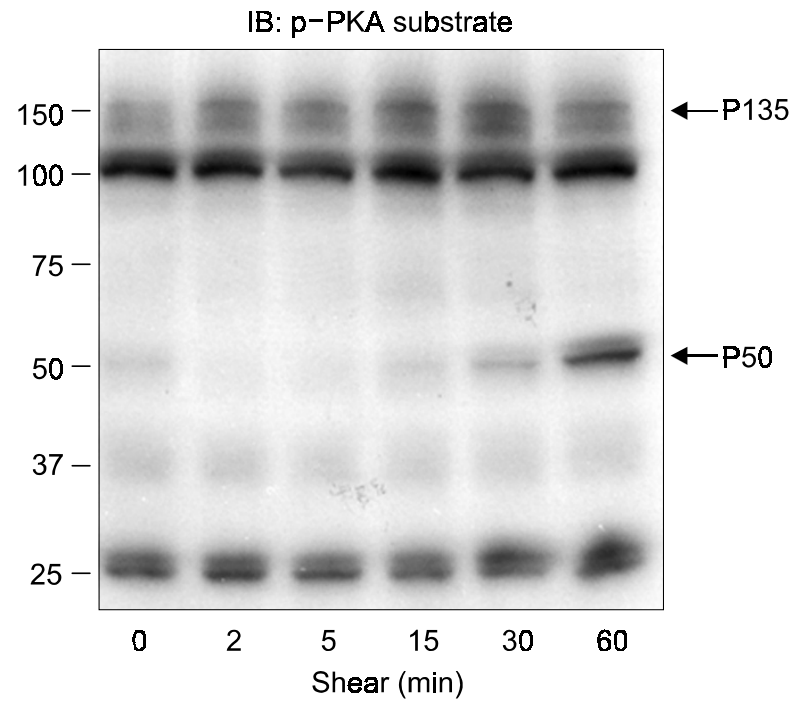

Figure 2. Shear stress stimulates phosphorylation of putative PKA substrates, P135 and P50, in endothelial cells. BAECs were exposed to shear stress for up to $60 \mathrm{~min}$. Cell lysates were analyzed by Western blot using the phospho-PKA substrate antibody.

using the phospho-PKA substrate antibody. This antibody would detect potential PKA substrates if they are phosphorylated. As shown in Figure 2, shear stress was found to stimulate the phosphorylation 


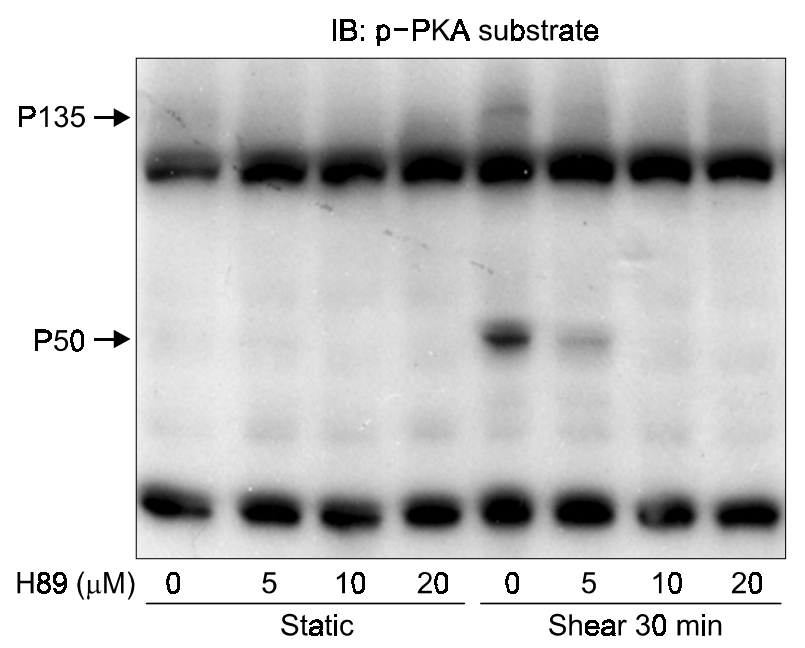

Figure 3. PKA inhibitor, $\mathrm{H} 89$, inhibits the phosphorylation of $\mathrm{P} 135$ and P50 stimulated by shear stress. BAECs were pretreated with vehicle (DMSO) or a PKA inhibitor (5 to $20 \mu \mathrm{M}$ H89) for $30 \mathrm{~min}$ before exposure to shear stress $\left(15 \mathrm{dyne} / \mathrm{cm}^{2}\right)$ for $30 \mathrm{~min}$. Cell lysates were analyzed by Western blot using the phospho-PKA substrate antibody.

\section{IB: $\mathrm{p}$-PKA substrate}
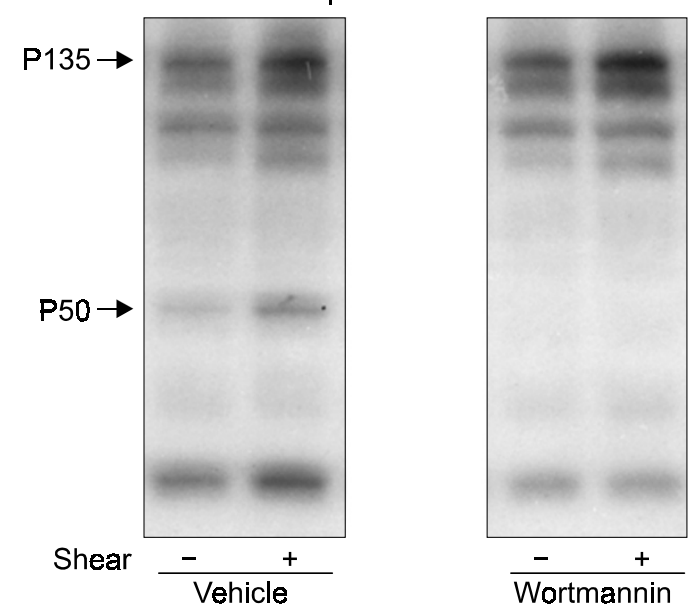

Figure 4. Shear-stimulated phosphorylation of P135 is insensitive to a PI3K inhibitor, wortmannin. BAECs were exposed to shear stress (15 dyne $/ \mathrm{cm}^{2}$ ) for $30 \mathrm{~min}$ in the absence or presence of PI3K inhibitor wortmannin $(100 \mathrm{nM})$. Cell lysates were analyzed by Western blot using the phospho-PKA substrate antibody.

of at least two putative PKA substrates with molecular masses of 135 (P135) and $50 \mathrm{kDa}$ (P50) detected by the phospho-PKA substrate antibody. The antibody also detected two other bands (molecular mass of 100 and $25 \mathrm{kDa}$ ) that appeared insensitive to shear stress (Figure 2).

Since the phospho-PKA substrate antibody may not be perfectly specific to PKA targets, the potential of P135 and P50 as physiological PKA substrates
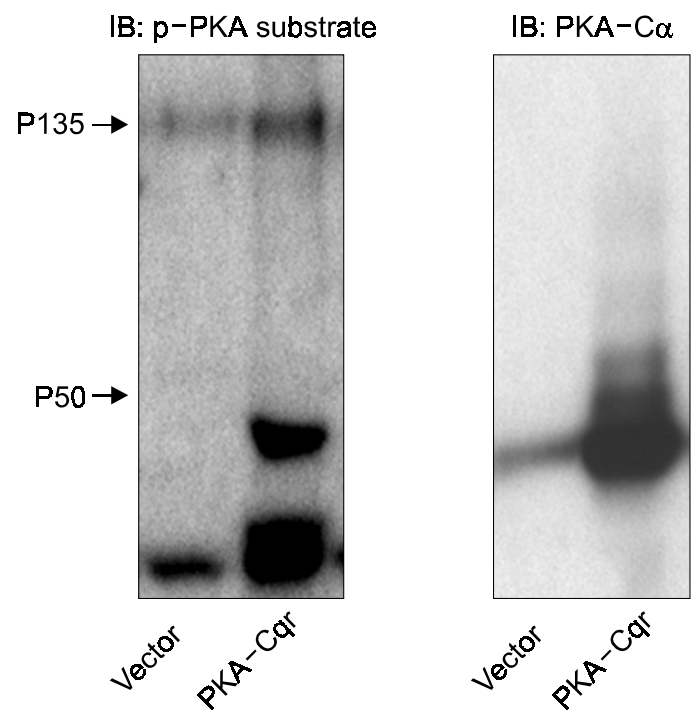

Figure 5. Expression of a constitutively active PKA subunit stimulates P135 phosphorylation. Subconfluent BAECs were transfected with the vector expressing PKA-Cgr or an empty pAdTrackCMV vector $(1 \mu \mathrm{g} /$ well). Cells were maintained in a growth medium for $24 \mathrm{~h}$ and then starved in a low-serum medium for $20 \mathrm{~h}$ before harvesting cells. The cell lysates were analyzed by Western blot using the pospho-PKA substrate antibody. The membranes were re-probed with PKA-C $\alpha$ antibody to show PKA-Cqr expression.

were further tested in following experiments. Summarizing the results, the shear-stimulated phosphorylation of P135 and P50 was mitigated by H89, a PKA inhibitor, in a dose-dependent manner (Figure 3). H89 inhibited the phosphorylation of both proteins significantly at as low as $5 \mu \mathrm{M}$. The P135 phosphorylation was insensitive to wortmannin, a highly specific phosphoinositide 3-kinase (PI3K) inhibitor, whereas the inhibitor blocked phosphorylation of P50 (Figure 4). Protein expression of a catalytically active PKACqr enhanced phosphorylation of P135 only (Figure $5)$. The results strongly supported the identity of P135 as a regulatory target of PKA, providing an additional evidence for PKA activation in response to shear stress in endothelial cells. It was also indicated that $\mathrm{P} 135$ might not be a downstream target of PI3K pathway, at least regarding the phosphorylation at the specific sites detected by the phospho-PKA substrate antibody. The potential of P50 as PKA substrate was questionable for its phosphorylation was not stimulated by PKA-Cqr expression (Figure 5). However this protein is expected to play a role in endothelial cell physiology because it appeared to be highly sensitive to shear stress.

\section{eNOS is a PKA substrate protein}

Previously, shear stress was shown to stimulate 


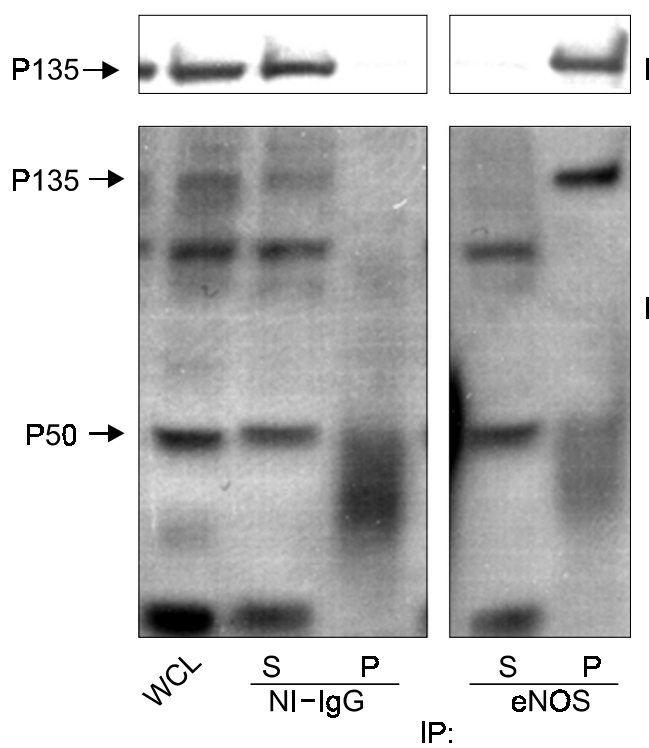

IB: eNOS

IB: $p$-PKA substrate

Figure 6. Identification of P135 as eNOS. BAECs were exposed to shear stress (15 $\mathrm{dyn} / \mathrm{cm}^{2}$ ) for $30 \mathrm{~min}$. Cell lysates were subjected to immunoprecipitation with an eNOS antibody or non-immune (NI) IgG immobilized on protein G-agarose beads. The supernatant $(S)$ and pellet from immunoprecipitation $(P)$ were compared with the whole cell lysates (WCL) by Western Blot using the phospho-PKA substrate antibody and eNOS antibody. Note that P135 was pulled down by eNOS antibody but not by NI-lgG. Furthermore P135 was detected by eNOS antibody.
eNOS phosphorylation in BAECs (Boo et al., 2002a; b). The characteristics of $P 135$, i.e. sensitivity to shear stress and apparent molecular weight on SDS-PAGE, prompted to examine if P135 is eNOS. BAECs were exposed to shear stress for $30 \mathrm{~min}$ and cells lysates were subjected to immunoprecipitation study. As shown in Figure 6, P135 was imunoprecipitated by monoclonal eNOS antibody but not by non-immune $\operatorname{lgG}$. The same band was detected when probed with either eNOS antibody or the pospho-PKA substrate antibody, identifying P135 as eNOS, which is known to mediate atheroprotective effect of laminar shear stress (Traub and Berk, 1998; Boo and Jo, 2003; Resnick et al., 2003; Cunningham and Gotlieb, 2005).

eNOS is a distinct $\mathrm{Ca}^{2+} / \mathrm{CaM}$-dependent enzyme. A putative 'auto-inhibitory element', a -50 amino acid residue segment present in the FMN-binding domain of eNOS impedes CaM binding to the enzyme, and thus high $\mathrm{Ca}^{2+}$ level is required for the enzyme activation (Nishida and Ortiz de Montellano, 1999; Chen and $\mathrm{Wu}, 2000)$. While $\mathrm{Ca}^{2+}$ is a major regulator of eNOS activity, it has become evident that eNOS activity is also regulated by other mechanisms such as protein-protein interactions and post-translational modifications. eNOS is subjected to myristoylation and palmitoylation which target the enzyme to the plasma membrane or Golgi (Sessa et al., 1993; Liu and Sessa, 1994).

eNOS phosphorylation as an activation mechanism was recognized only recently but the evidence supporting its importance has grown rapidly (Dimmeler et al., 1999; Fulton et al., 1999). Currently, 5 Ser/Thr residues (Ser116, Thr497, Ser617, Ser635 and Ser1179) are known to be phosphorylated by numerous protein kinases including PKA, protein kinase B (Akt), CaM kinase II, AMP-activated kinase and protein kinase $C$ in response to physiological stimuli (Michell et al., 2002; Boo and Jo, 2003). In our previous studies, the stimulation of PKA by treating BAECs with a cell-permeable cAMP analog, 8-Br-cAMP, was found to enhance the phosphorylation of eNOS at Ser635 and Ser1179 (Boo et al., 2002b). Expression of PKA-Cqr also stimulated eNOS phosphorylation at those sites (Boo et al., 2003). Furthermore, shear stress appeared to stimulate the phosphorylation of eNOS at Ser635 and Ser1179 which was inhibited by PKA inhibitor, H89, or adenovirus-mediated expression of PKI peptide (Boo et al., 2002b). Therefore eNOS-Ser635 and Ser1179 are potential PKA sites.

It is currently viewed that while PKA phosphorylates eNOS at Ser1179 and Ser635, protein kinase B (Akt) phosphorylates Ser1179 and Ser617 in vitro and in cells (Dimmeler et al., 1999; Fulton et al., 1999; Butt et al., 2000; Boo et al., 2002a; Michell et al., 2002). Because both PKA and Akt can phosphorylate eNOS at Ser1179 in common, and they share consensus sequences, I further examined if the phospho-PKA substrate antibody detects eNOS phosphorylated by Akt. As shown in Figure 7, expression of a constitutively active Akt mutant resulted in robust eNOS phosphorylation at Ser1179 that was insensitive to H89. However, the Akt-dependent eNOS phosphorylation, including that of Ser1179, was not detected by the phospho-PKA substrate antibody used in the present study, indicating that the antibody is highly specific to the PKA sites. Because the antibody did not detect eNOS phosphorylated at Ser1179, it was suggested that the other 


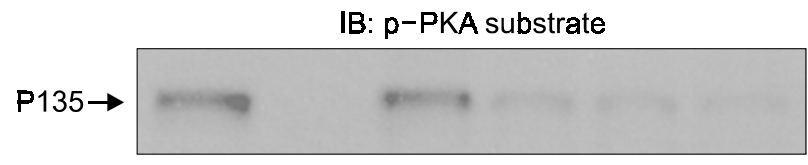

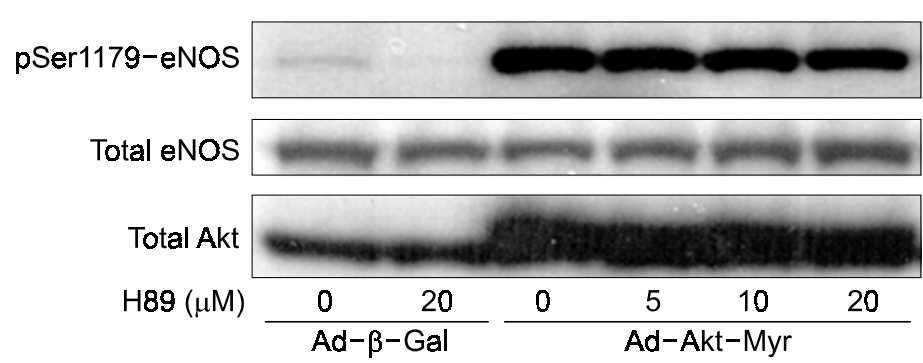

Figure 7. The phospho-PKA substrate antibody does not cross-react with Akt sites in eNOS. BAECs were infected with a recombinant adenovirus (Ad-Akt-Myr) expressing a constitutively active Akt mutant or a control adenovirus encoding $\beta$-galactosidase (Ad- $\beta$-Gal) at $50 \mathrm{MOI}$. The infected cells were treated with 5 to $20 \mu \mathrm{M} \mathrm{H} 89$ for $60 \mathrm{~min}$. The cell lysates were analyzed by Western blot using the phospho-PKA substrate antibody, phospho-Ser1179-eNOS, total eNOS antibody and total Akt antibody.

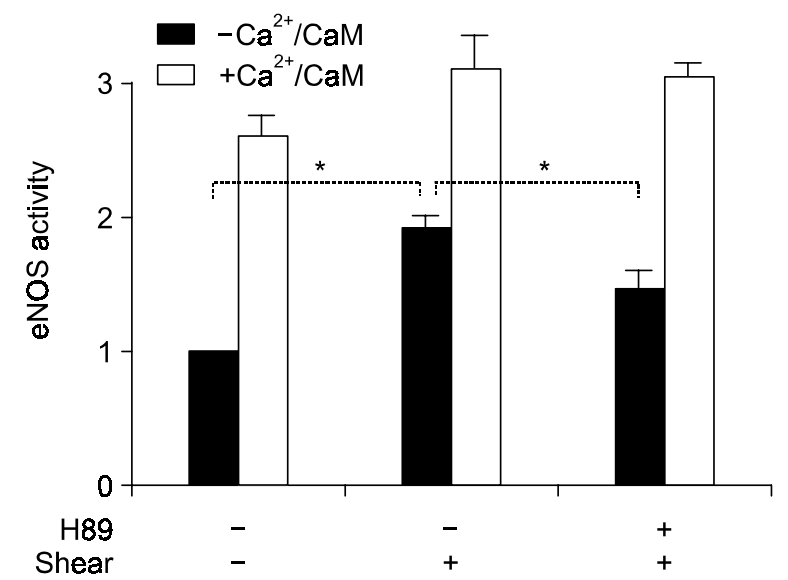

Figure 8. PKA regulates eNOS activation by shear stress. BAECs were pretreated with vehicle (DMSO) or a PKA inhibitor (10 $\mu \mathrm{M} \mathrm{H89)}$ for $30 \mathrm{~min}$ before exposure to shear stress $\left(15 \mathrm{dyn} / \mathrm{cm}^{2}\right)$ for $30 \mathrm{~min}$. eNOS activity in cell lysates was determined by L-NAME-inhibitable conversion of $\mathrm{L}$-arginine to L-citrulline using $\left.{ }^{3} \mathrm{H}\right] \mathrm{L}$-arginine as a tracer. The activity was measured in the presence and absence of added $\mathrm{Ca}^{2+} / \mathrm{CaM}$. The basal activity was $0.13 \mathrm{nmol} / \mathrm{mg}$ protein $/ \mathrm{min}$ when assayed without addition of $\mathrm{Ca}^{2+} / \mathrm{CaM}$. Relative activities are shown. Data represent mean $\pm \operatorname{SEM}(n=3)$. ${ }^{*} P<0.05$.

potential PKA site, Ser635, might be the site detected by the antibody.

\section{PKA regulates eNOS activity in response to shear stress}

Given that PKA phosphorylates eNOS, I next examined whether PKA regulates eNOS activation in response to shear stress. For this purpose, BAECs were pretreated with vehicle or $\mathrm{H} 89$ and exposed to shear stress for $30 \mathrm{~min}$, and eNOS activity in the cell lysates was determined by the catalytic activity converting L-arginine to L-citrulline. The assay was performed at two different conditions where $\mathrm{Ca}^{2+}$ and $\mathrm{CaM}$ were supplemented or not. As shown in Figure 8, shear stress stimulated eNOS activation significantly when assayed without of $\mathrm{Ca}^{2+} / \mathrm{CaM}$ supplementation. Furthermore, PKA inhibitor H89 attenuated the activation of eNOS significantly.

In our previous study, eNOS mutant, in which Ser635 was changed to Asp to mimic phosphorylation status, was found to have several fold higher activity than wild type in cells (Boo et al., 2003). The activity difference between the mutant and wild type became insignificant when the cellular $\mathrm{Ca}^{2+}$ level was elevated maximally by treating the cells with $\mathrm{Ca}^{2+}$ ionophore. The results shown in Figure 8 are comparable to those previous findings, as the effects of shear stress and PKA inhibition were not seen if $\mathrm{Ca}^{2+}$ and $\mathrm{CaM}$ were included in the assay mixture. Therefore, it is suggested that PKA-dependent eNOS phosphorylation provides a compensatory mechanism for the enzyme activation without involving intracellular $\mathrm{Ca}^{2+}$ increase. In consistent with this notion, a critical role of PKA in vascular nitric oxide production as a compensatory mechanism has also been demonstrated previously in coronary blood vessels (Zhang and Hintze, 2001).

\section{Shear stress stimulates intracellular translocation of PKA}

To take insight into how PKA is stimulated by shear stress in endothelial, I also determined total cellular cAMP level in BAECs exposed to shear stress, but could not observe any increase (Data not shown), in agreement with a previous study (Malek et al., 1993). When determined by a conventional method using Kemptide as a PKA substrate, with cAMP supplement, the PKA activity in the pelleted 'particulate' fractions was significantly increased although in supernatant 'soluble' fractions tended to decrease, as shown in Figure 9. This result is not merely surprising, because nuclear signaling involving CREB 


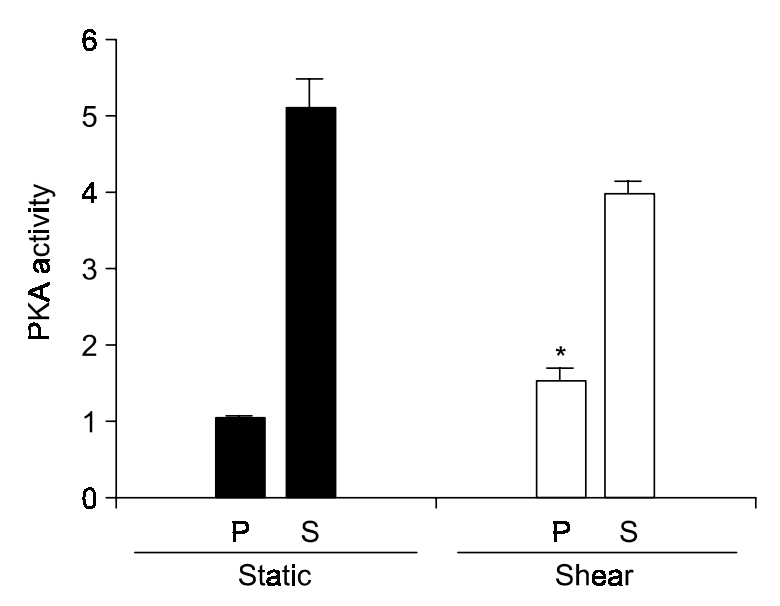

Figure 9. Shear stress stimulates intracellular translocation of PKA activity. BAECs were exposed to shear stress $\left(15 \mathrm{dyn} / \mathrm{cm}^{2}\right)$ for 30 min. Control cells were kept under static condition for the same time period. Cells were homogenized and centrifuged at $15,000 \mathrm{rpm}$ for $15 \mathrm{~min}$ to separate supernatant $(\mathrm{S})$ and pellet $(\mathrm{P})$. Both supernatant and pellet fractions were subjected to PKA activity assay using Kemptide as a PKA substrate, with CAMP supplementation, in the presence and absence of PKA inhibitor, PKI. The data are presented as PKI-inhibitable phosphorylation of Kemptide. Relative activities are shown. Data represent mean \pm SEM $(n=3)$. ${ }^{*}, P<0.05$ vs. static control.

activation should require the translocation of the free PKA catalytic subunit to the nucleus (Sastri et al., 2005). Furthermore, membrane targeting of eNOS to the plasma membrane or Golgi appears to be critical for the phosphorylation by protein kinases (Gonzalez et al., 2002; Fulton et al., 2004). Although the preparations used in this experiment are not fully informative in terms of organelle composition, it is conceivable that shear stress may stimulate PKA interaction with its substrates, i.e. eNOS, in an intracellular location-specific manner. Recent studies have demonstrated that cell-cell contact induces the enrichment of eNOS at intercellular junctions (Govers et al., 2002). Because eNOS is associated with PKA catalytic subunit at endothelial cell junctions (Heijnen et al., 2004), it would be interesting to examine whether their interaction is altered by shear stress.

In conclusion, the current study provided evidence that the PKA activity is stimulated by shear stress based on the phosphorylation of PKA substrates expressed in endothelial cells. Phosphoprotein analysis using the phospho-PKA substrate antibody identified eNOS as one of the major regulatory targets of PKA stimulated by shear stress in endothelial cells. Although PKA had been implicated in eNOS regulation previously, the current study clearly demonstrated the presence of PKA-specific phosphorylation sites in eNOS. The shear-stimulated intracellular translocation of PKA activity implies that shear stress may stimulate site-specific interaction between PKA and target proteins.

\section{Acknowledgement}

This work was supported by BioMedical Research Institute grant, Kyungpook National University Hospital (2005).

\section{References}

Berk BC, Min W, Yan C, Surapisitchat J, Liu Y, Hoefen R. Atheroprotective mechanisms activated by fluid shear stress in endothelial cells. Drug News Perspect 2002;15:133-9

Boo YC, Hwang J, Sykes M, Michell BJ, Kemp BE, Lum $\mathrm{H}$, Jo $\mathrm{H}$. Shear stress stimulates phosphorylation of eNOS at Ser (635) by a protein kinase A-dependent mechanism. Am J Physiol Heart Circ Physiol 2002a;283:H1819-28

Boo YC, Jo H. Flow-dependent regulation of endothelial nitric oxide synthase: role of protein kinases. Am J Physiol Cell Physiol 2003;285:C499-508

Boo YC, Sorescu G, Boyd N, Shiojima I, Walsh K, Du J, Jo $H$. Shear stress stimulates phosphorylation of endothelial nitric-oxide synthase at Ser1179 by Akt-independent mechanisms: role of protein kinase A. J Biol Chem 2002b;277:3388-96

Boo YC, Sorescu GP, Bauer PM, Fulton D, Kemp BE, Harrison DG, Sessa WC, Jo H. Endothelial NO synthase phosphorylated at SER635 produces $\mathrm{NO}$ without requiring intracellular calcium increase. Free Radic Biol Med 2003;35:729-41

Brandon EP, Idzerda RL, McKnight GS. PKA isoforms, neural pathways, and behaviour: making the connection. Curr Opin Neurobiol 1997;7:397-403

Butt E, Bernhardt M, Smolenski A, Kotsonis P, Frohlich LG, Sickmann A, Meyer HE, Lohmann SM, Schmidt HH. Endothelial nitric-oxide synthase (type III) is activated and becomes calcium independent upon phosphorylation by cyclic nucleotide-ependent protein kinases. J Biol Chem 2000;275:5179-87

Chen PF, Wu KK. Characterization of the roles of the 594-645 region in human endothelial nitric-oxide synthase in regulating calmodulin binding and electron transfer. J Biol Chem 2000; 275:13155-63

Cheng X, Ma Y, Moore M, Hemmings BA, Taylor SS. Phosphorylation and activation of cAMP-dependent protein kinase by phosphoinositide-dependent protein kinase. Proc Natl Acad Sci USA 1998;95:9849-54

Cunningham KS, Gotlieb Al. The role of shear stress in the pathogenesis of atherosclerosis. Lab Invest 2005;85:942

Daniel PB, Walker WH, Habener JF. Cyclic AMP signaling and gene regulation. Annu Rev Nutr 1998;18:353-83

Davies PF. Multiple signaling pathways in flow-mediated endothelial mechanotransduction: PYK-ing the right location. Arterioscler Thromb Vasc Biol 2002;22:1755-7

Dimmeler S, Fleming I, Fisslthaler B, Hermann C, Busse R, Zeiher AM. Activation of nitric oxide synthase in endothelial cells by Akt-dependent phosphorylation. Nature 1999;399: 
$601-5$

Dulin NO, Niu J, Browning DD, Ye RD, Voyno-Yasenetskaya T. Cyclic AMP-independent activation of protein kinase A by vasoactive peptides. J Biol Chem 2001;276:20827-30

Dusserre N, L'Heureux N, Bell KS, Stevens HY, Yeh J, Otte LA, Loufrani L, Frangos JA. PECAM-1 interacts with nitric oxide synthase in human endothelial cells: implication for flow-induced nitric oxide synthase activation. Arterioscler Thromb Vasc Biol 2004;24:1796-802

Fleming I, Fisslthaler B, Dixit M, Busse R. Role of PECAM-1 in the shear-stress-induced activation of Akt and the endothelial nitric oxide synthase (eNOS) in endothelial cells. J Cell Sci 2005;118:4103-11

Fujio Y, Walsh K. Akt mediates cytoprotection of endothelial cells by vascular endothelial growth factor in an anchoragedependent manner. J Biol Chem 1999;274:16349-54

Fulton D, Babbitt R, Zoellner S, Fontana J, Acevedo L, McCabe TJ, Iwakiri Y, Sessa WC. Targeting of endothelial nitric-oxide synthase to the cytoplasmic face of the Golgi complex or plasma membrane regulates Akt- versus calcium-dependent mechanisms for nitric oxide release. J Biol Chem 2004;279: 30349-57

Fulton D, Gratton JP, McCabe TJ, Fontana J, Fujio Y, Walsh K, Franke TF, Papapetropoulos A, Sessa WC. Regulation of endothelium-derived nitric oxide production by the protein kinase Akt. Nature 1999;399:597-601

Gonzalez E, Kou R, Lin AJ, Golan DE, Michel T. Subcellular targeting and agonist-induced site-specific phosphorylation of endothelial nitric-oxide synthase. J Biol Chem 2002;277: 39554-60

Govers R, Bevers L, de Bree P, Rabelink TJ. Endothelial nitric oxide synthase activity is linked to its presence at cell-cell contacts. Biochem J 2002;361:193-201

Heijnen HF, Waaijenborg S, Crapo JD, Bowler RP, Akkerman JW, Slot JW. Colocalization of eNOS and the catalytic subunit of PKA in endothelial cell junctions: a clue for regulated NO production. J Histochem Cytochem 2004;52:1277-85

Illi B, Nanni S, Scopece A, Farsetti A, Biglioli P, Capogrossi MC, Gaetano C. Shear stress-mediated chromatin remodeling provides molecular basis for flow-dependent regulation of gene expression. Circ Res 2003;93:155-61

Liu J, Sessa WC. Identification of covalently bound aminoterminal myristic acid in endothelial nitric oxide synthase. J Biol Chem 1994;269:11691-4

Malek AM, Greene AL, Izumo S. Regulation of endothelin 1 gene by fluid shear stress is transcriptionally mediated and independent of protein kinase $C$ and CAMP. Proc Natl Acad Sci USA 1993:90:5999-6003

Michell BJ, Harris MB, Chen ZP, Ju H, Venema VJ, Blackstone MA, Huang W, Venema RC, Kemp BE. Identification of regulatory sites of phosphorylation of the bovine endothelial nitric-oxide synthase at serine 617 and serine 635 . J Biol Chem 2002;277:42344-51
Min KJ, Yang MS, Jou I, Joe EH. Protein kinase A mediates microglial activation induced by plasminogen and gangliosides. Exp Mol Med 2004;36:461-7

Nagai Y, Miyazaki M, Aoki R, Zama T, Inouye S, Hirose K, lino $M$, Hagiwara M. A fluorescent indicator for visualizing cAMP-induced phosphorylation in vivo. Nat Biotechnol 2000; 18:313-6

Nishida CR, Ortiz de Montellano PR. Autoinhibition of endothelial nitric-oxide synthase. Identification of an electron transfer control element. J Biol Chem 1999;274:14692-8

Niu J, Vaiskunaite R, Suzuki N, Kozasa T, Carr DW, Dulin $\mathrm{N}$, Voyno-Yasenetskaya TA. Interaction of heterotrimeric G13 protein with an A-kinase-anchoring protein 110 (AKAP110) mediates cAMP-independent PKA activation. Curr Biol 2001; 11:1686-90

Orellana SA, McKnight GS. Mutations in the catalytic subunit of cAMP-dependent protein kinase result in unregulated biological activity. Proc Natl Acad Sci USA 1992;89:4726-30

Park SA, Kim TS, Choi KS, Park HJ, Heo K, Lee BI. Chronic activation of CREB and p90RSK in human epileptic hippocampus. Exp Mol Med 2003;35:365-70

Razani B, Rubin CS, Lisanti MP. Regulation of cAMP-mediated signal transduction via interaction of caveolins with the catalytic subunit of protein kinase A. J Biol Chem 1999;274:26353-60

Reich KM, Gay CV, Frangos JA. Fluid shear stress as a mediator of osteoblast cyclic adenosine monophosphate production. $\mathrm{J}$ Cell Physiol 1990;143:100-4

Resnick N, Yahav H, Shay-Salit A, Shushy M, Schubert S, Zilberman LCM, Wofovitz E. Fluid shear stress and the vascular endothelium: for better and for worse. Progress in Biophysics and Molecular Biology 2003;81:177-99

Sastri M, Barraclough DM, Carmichael PT, Taylor SS. A-kinase-interacting protein localizes protein kinase $A$ in the nucleus. Proc Natl Acad Sci USA 2005:102:349-54

Sessa WC, Barber CM, Lynch KR. Mutation of N-myristoylation site converts endothelial cell nitric oxide synthase from a membrane to a cytosolic protein. Circ Res 1993;72:921-4

Sheng M, Thompson MA, Greenberg ME. CREB: a Ca (2+)-regulated transcription factor phosphorylated by calmodulin- dependent kinases. Science 1991;252:1427-30

Traub O, Berk BC. Laminar shear stress: mechanisms by which endothelial cells transduce an atheroprotective force. Arterioscler Thromb Vasc Biol 1998;18:677-85

Wei L, Muller S, Ouyang J, Stoltz JF, Wang X. Changes of vasodilator-stimulated phosphoprotein (VASP) and its phosphorylation in endothelial cells exposed to laminar flow. Clin Hemorheol Microcirc 2003;28:113-20

Zhang $X$, Hintze TH. cAMP signal transduction cascade, a novel pathway for the regulation of endothelial nitric oxide production in coronary blood vessels. Arterioscler Thromb Vasc Biol 2001;21:797-803 


\section{Retraction}

Shear stress stimulates phosphorylation of protein kinase A substrate proteins including endothelial nitric oxide synthase in endothelial cells.

2006 Feb 28;38(1):63-71.

Boo YC.

Department of Molecular Medicine, Kyungpook National University School of Medicine, Daegu 700-422, Korea. ycboo@knu.ac.kr

This article is retracted by the request of the corresponding author. The corresponding author is deeply sorry for any inconvenience this may have caused to the Experimental and Molecular Medicine and to the readers. 